\title{
Ouyang Xiu's Autobiography in Perspective of Chinese and Western Narratologies
}

\author{
WANG Ying \\ Female,Associate Professor,Research Fellow, FRASInstitute of Literature, Chinese Academy of Social \\ Sciences,No.5 Jianguomennei Dajie, Dongcheng District, Beijing 100732,China.
}

\begin{abstract}
Liuyi Jushi Zhuan(The Biography of Hermit Six Ones), the autobiography of Ouyang Xiu, is a distinguished biography with superb narrative techniques. Analyzed in perspective of Chinese and Western narratologies, The Biography of Hermit Six Ones shows structural skills of "metanarrative signs" and superb narrative experience of imagery applications, introspection and satire in narrative perspective-apologias and interior monologues. In terms of the theory of Roland Barthes, its rich and complex meaning world can clearly summarize the relation between the author and the literary representation of his self-image.
\end{abstract}

Key Words: Ouyang Xiu; Liu Yi Jushi Zhuan; Six ones; Chinese \& Western Narratology

As a "literary master" of the Northern Song Dynasty (960AD-1127AD) China, Ouyang Xiu stood out in many cultural fields. Li Chunqing has made incisive comments on the profound reasons why Ouyang Xiu was the scholar representative of his era, "The reason why Ouyang Xiu was the spiritual model of contemporary scholars is that he advocated and upheld personal ideals when scholarly subject consciousness was seriously lost after the late Tang Dynasty (618AD-907AD), the Five Dynasties (907AD-960AD) and the early Song Dynasty (960AD-1279AD). In addition to his talent and genius, he became a literary leader because his numerous academic expressions, literature theory and works coincided with and represented common spirit states and value expectations of the scholarly class then, and his literary expressions (theories) could be regarded as characterizations of scholarly personality ideals." $"$ "The scholar class also had intense desire for purely individual spirit worlds. They wished they could often stay in interior worlds that are absolutely pure and away from the vulgar world so that they could enjoy blissful periods with mental freedom. In this regard, Ouyang Xiu was also a representative of scholars." 2

The Biography of Hermit Six Ones is a perfect representation of his era-leading elegant taste and spiritual world. The life tastes that Ouyang Xiu narrated in his biography - reading, inscription appreciation, zither playing, chess playing and wine drinking - were popular hobbies of the scholar class in his time. Having collected one thousand volumes of rubbings, he was a famous epigraphist, the pioneer and founder of Chinese epigraphy.

Hermit Six Ones was relegated to the village of Chuzhou, he gave himself an alias:OldDrunkard.He is old,weak and ill.Now he is going to farewell officialdom,then goes to the side of Ying River, and plans to live out his life and die in peace.Therefore he changed his alias to Hermit Six Ones.

A guest asked, "What do Six Ones refer to?" The hermit replied: "I have collected 10,000 volumes of books, 1000 volumes of rubbings of ancient metal and stone tablets from the Xia(around 21th century BC-16th century BC),Shang(around 1675BC-1029BC) and Zhou(the middle period of 11 century BC-256 BC) Dynasties; I have a musical instrument, a plate of chess pieces, and I often get ready a pot of wine." The guest said, "Those only make five ones, but why do you call yourself "Six Ones'?" The hermit answered, "Plus me, one old man living among these five ones, will that not make 'Six Ones'?"

The guest laughed saying, "You must be someone that wants to evade the reputation(keep a low profile), that's why you changed your names so often? Just like the man mocked by Chuang Tse would often run into the sunshine for fearing his shadow, I will see you behave like that man, running fast, gasping deeply, and dying out of thirst, and yet still unable to escape from fame." The hermit explained: "I know I cannot escape from fame and I also know I do not need to; I give myself this name just used to indicate my pleasure." The guest asked, "What is your pleasure like?" The hermit answered, "How can I speak enough of my pleasure! When I

\footnotetext{
${ }^{1}$ Li Chunqing: Songxue Yu SongdaiWenxueGuannian (Learning and literature concept of the Song Dynasty)[M]. Beijing: Beijing Normal University Publishing Group,2001. pp.138-39.
}

${ }^{2}$ Ibid. pp. 142 . 
am intoxicated while playing among these five ones, I cannot see Mount Tai even if it is just before me, and I am not surprised even if the thunder splits the pillar; even if the ancient music Jiushao [Name of a piece of music during Shun Times(2255BC-2208BC) ]was played on Dongting Lakeand I could watch big battles in the field of Zhuolu, all of these can hardly depict my pleasure and comfort. Nevertheless, I often worry that I cannot indulge myself among these five ones and the reason is that I have been tied up by affairs of my life. Among them, there are two big affairs. The first is that the official vehicle, robe, passport and seal make me feel tired from outside; and the second is that worries and anxieties make me feel tired inside. These make me look ill when I am not sick and spiritually exhausted when I am not old; how can I find leisure to play among these five ones? Even though this is the case, I have pled to the imperial court for retirement for three years, if one day the emperor took pity on me and my old bones, letting me return to pastoral with my five ones; then I can hopefully realize my long-cherished dream. This is the reason for indicating my pleasure." The guest laughed saying: "You only know the official vehicle, robe, passport and seal may wear you out, but don't you know that these five ones may also make your heart feel tired?" The hermit said: "These are not the same. I am worn out by the official affairs because I am already tired and I have many worries; but when attracted by these five things, I feel comfortable and I rejoice that there is no disaster. What choice shall I make?" So saying, the hermit stood up with the guest, shook his hands and laughed: "Let us stop arguing. Such trifles are not worth our concern ."

Later, the hermit sighed: "A scholar began his official career when he was young. Till he becomes old and retires, he normally can hardly wait for his retiring age of 70. I usually admire such people, so this is the first reason I want to retire. I have been working for the court, but till now I have not made any achievement worthy of praise. This is the second reason I want to retire. When young and strong, my career was just so so, now I am old and ill, with a weak body I can hardly support to pursue the undeserved official position and the salary; this goes against my normal will, just like eating my own words. This is the third reason that I should retire. I have these three reasons to retire, even if there are no five ones to attract me, leaving office is sensible. What else should I say!"

Sep. $7^{\text {th }}$, the third year of Xining(reign title of Emperor Song Shenzong, the third year of Xining is 1070),Hermit Six Ones wrote autobiography by himself.

In his autobiography, Ouyang Xiu explained the meaning of his pseudonym, "I have collected 10,000 volumes of books, 1,000 volumes of rubbings of ancient metal and stone tablets from the Xia(around 21th century BC- 16th century BC), Shang(around 1675BC-1029BC) and Zhou(the middle period of 11 century BC-256 BC) Dynasties; I have a musical instrument, a plate of chess pieces, and I often get ready a pot of wine.......Plus me, one old man living among these five ones, will that not make 'Six Ones'?"1 In the concept of "Six Ones", "I" was also a part. The equality and apposition of "physical taste" and "I" indicated that the author treated and united them equally, showing his serene mentality to enjoy nature, freedom, agedness and tranquility. However, the author also exposed his sadness and helplessness at the end of the biography. The whole article is penetrated with questions and answers, and concluded with the words "biography of Hermit Six Ones" to explicitly demonstrate his seclusive aspiration. In perspective of Chinese and Western narratologies, as a narrative prose, The Biography of Hermit Six Ones surpassed previous works in many innovations that were not limited in the biographic field. It is also a classic prose in the Tang and the Song dynasties, revealing the eminent conceptions of Ouyang Xiu in narrative implications and techniques that deserve profound exploration in way of Chinese and Western narratologies.

\section{STRUCTURAL TECHNIQUES OF “METANARRATIVE SIGNS” FUNCTIONS AND IMAGERY APPLICATIONS IN THE CONCEPTION OF "SIX ONES"}

Gerald Prince, a US narrative expert, has expounded functions of metanarrative signs in Western narratology, "The most evident metanarrative signs - though not necessarily the most numerous or the most important - are probably those which comment on linguistic code units. A text may define an esoteric expression,...A narrator may also explain the meaning od an element in his lexicon because he is using it in a rather special way".2،"Given any narrative passage, metanarrative signs can thus indicate its functioning in a series of codes. They can explain its linguistic, sociocultural, or symbolic meaning. They can point out that a certain behavior or a certain state of things represents an enigma or a solution to that enigma....The metanarrative sign "Six Ones" has fully shown the nature of a series of events that belong to the same proairetic

\footnotetext{
${ }^{1}$ Ouyang Xiu:LiuyiJushiZhuan(The Biography of Hermit Six Ones)[A].Hong Benjian proofread and noted:OuyangXiuShiwenjiJiaojian(The Collection of Ouyang Xiu's Poetry and Articles with Proofreading and Explanatory Notes)[M]. Shanghai: Shanghai Ancient Books Publishing House,2014.pp.1130-31.
}

${ }^{2}$ Gerald Prince:Narratology:The Form and Functioning of Narrative[M].Berlin:Mouton De Gruyter,1982.pp.121. 
sequence and can name the sequence"1.

If The Biography of Hermit Six Ones is examined with this concept, the "Six Ones" - five hobbies of his elegant tastes and personal pursuance plus the author himself - are apparently metanarrative signs as "he is using it in a rather special way"2. Each "One" has its denotation. Following the stimulation of the title to readers in curiosity and knowledge desire, subsequent explanation in the text of each "One""represents a mystery and its exposition" accompanied by an explicit expression "I give myself this name just to indicate my pleasure. ${ }^{3}$ The metanarrative signs"Six Ones"have also fully shown the nature of a series of events that belong to the same proairetic sequence and can name the sequence.

Therefore, the narrative mode of The Biography of Hermit Six Ones can be "sometimes employing narrative analysis and sometimes we might call physical correlatives to symbolize mental states." In addition to being metanarrative signs, as a design for special images, "Six Ones" also effectively reflected the author's marvelous narrative skills and brilliant structural layout, that is, "By using ...other physical objects to symbolize ....mental states,...is able to project the desired image of ...psyche without relying heavily on narrative analysis and impeding the limpid flow of the narrative, and without heightening and distorting the language of ...thoughts." "Designed to perform some of the work of characterization which would otherwise require more in the way narrative analysis or interior monologue."

Therefore, as the setting of metanarrative signs, "Six Ones" has not only fulfilled its necessary functions, but also represents a brilliant conception in view of imagery applications.

Besides the grand meaning world created by "Six Ones" as a unique symbol, what else special connotation did Ouyang Xiu give to the digital symbol in his biography? What cultural background and ideological origin did it have in Chinese narratology? Yang Yi has discussed "figure" application in narrative literature in his work Chinese Narrative, "Because of impacts of primitive belief and wizardry, some special figures indicate universal mysteries, and their applications often contain some philosophical meanings or religious mysteries so that they can be associated with structural rules. However, figures can be ordered or combined in daily life. Therefore, adoptions of some figures can reinforce narrative sequences or combination intensities of narrative units so that figures can have close relations with structural techniques. "7"One" has a very long history as the original symbol of universal matters and the statement of Lao-tze "Dao produces One, One produces Two, Two produces Three, and Three produces Everything" ${ }^{8}$ has laid philosophical foundations for this ideology, and "One" becomes a product of "Dao". In addition to its symbolic meaning as the original status of universal matters, "One" also represents some transcendent and peerless singularity; Chuang Tzu also said, "The heaven and the earth and I came into existence at the same time; all things in the world and I are one uniformity" ${ }^{9}$, which represents Daoist harmony and uniformity between man and nature. It can be said that the first five "Ones" of Ouyang Xiu's six "Ones" are combinations of the first two implications, and the sixth "One" - "I" - is the materialization of the third implication, and also the ultimate purpose of the image setting of his "Six Ones".

Yang Yi has discussed the image role in narrative works in Chinese Narrative, "As the 'central phrase' of an article, image has the function of cohering significance and spirit. .....Therefore, when image symbolically penetrates the context, it can be a spotlight and pool of meanings, making adjustment of meaning expansion and condensation and mechanism of meaning transformations. "10"Once condensed, meanings will become projected,

${ }^{1}$ Ibid. pp. 123 .

${ }^{2}$ Ibid. pp. 121 .

${ }^{3}$ LiuyiJushiZhuan(The Biography of Hermit Six Ones). pp.1130-31.

${ }^{4}$ Narratology:The Form and Functioning of Narrative.pp.196.

${ }^{5}$ Ibid. pp. 196.

${ }^{6}$ Ibid. pp.199.

${ }^{7}$ Yang Yi:ZhongguoXushixue(Chinese Narrative)[M].Beijing:China Social Sciences Press,2007.pp.35-36.

${ }^{8} \mathrm{Li}$ Er:Laws Divine and Human[M].Translated into English by Xu Yuanchong. Beijing:China Intercontinental Press\&Zhonghua Book Company,2011. pp.49.

${ }^{9}$ Zhuang Zhou:Zhuangzi[M].Translated into English by Wang Rongpei. Changsha: Hunan People's Publishing House \& Beijing: Foreign Languages Press,1999. pp.29.

${ }^{10}$ ZhongguoXushixue(Chinese Narrative). pp.222. 
concentrated and distinct with intense aesthetic tastes or powerful impacts. Particularly, those unique and unusual images can enhance narration with powerful psychological effects." ${ }^{1}$ The image of "Six Ones" created by and exclusively belongs to Ouyang Xiu penetrates the whole article of Biography of Hermit Six Ones, and is undoubtedly a penetrating and cohering centripetal force. Under the theme of retirement and seclusion, the five "Ones" representing elegant tastes and spiritual pursuits of the author combine with "I" from the very beginning of the article to be "Six Ones". However, the "Six Ones" are actually a whole and transform into a "matter-ego oneness". At the end of the article, Ouyang Xiu exposed his true mind, "I have these three reasons to retire, even if there are no five ones to attract me, leaving office is sensible. What else should I say!" "Taking the five "Ones" "Ones" external objects against his personality pursuance and spirit freedom, and separating "I" from such five "Ones", Ouyang Xiu finally played the full role of "Six Ones" in narration. From the beginning integration of "I" and five "Ones" into "Six Ones" as a whole to the ending separation, the convergence and separation of "I" and "Objects" have revealed the eminent techniques of Ouyang Xiu to masterfully use images.

In addition to image convergence and separation of "Six Ones" as "metanarrative signs" and "special images" in narrative evolution of the article, and vague tips for meaning association, Ouyang Xiu has also made special arrangements in the narrative mode of questions and answers between him and a guest, which contains noticeable value judgment. "Metanarrative signs tend to reveal how a given narrator views the knowledge and sophistication the audience he is addressing: the metanarrative explanations which he feels obliged to provide and the degree of tact which he manifests in providing them show what he thinks of his narratee, whether he respects him, is well disposed towards him, or considers himself to be infinitely superior; and the distribution of these explanations may point to a change in the relationship between the two:if the narrators stop making metalinguistic statements, for instance, it may be because he has understood that his narratee can do without them.",3

In the article, from the beginning humor when "Hermit Six Ones" starts to answer questions of the guest to rich experience and profound analysis in the middle and then to active termination of the conversation in the end, "So saying, the hermit stood up with the guest, shook his hands and laughed: 'Let us stop arguing. Such trifles are not worth our comparison"," Ouyang Xiu completely disagreed with his "guest" who represents the worldly worldly mentality full of sharp questions and bitter challenges, so he refused to answer and ended the conversation. The active termination of metalinguistic statements of Hermit Six Ones as the narrator is only because "he realized that his audience didn't need them", and his rigorous answers and painstaking explanations at the beginning changed into active termination in the end.The termination of the conversation suggested that apposition transformed into deviation between the host and guest. The value orientation for life "happiness" of Ouyang Xiu has been effectively exposed during the beginning, advancing and ending of the conversation.

\section{INTROSPECTION AND SATIRE IN NARRATIVE PERSPECTIVE - APOLOGIAS AND INTERIOR MONOLOGUES}

Another important narrative feature of The Biography of Hermit Six Ones is mobility and transformation in narrative perspective, which is critical for indirectly and profoundly unveiling "my" internal world. "Perspective is to feel, observe and know the narrative world from the standpoint of the author and narrator;" 5 "Narrative perspective is a composite index and a hub for narrative strategies that complexly associates who is viewing, what people and matters he has seen, and what attitudes the observer and the observed hold, and what 'summon horizon' is offered to the reader." 6 "Unique horizon operations can produce philosophical functions and make profound social and life introspections." The Biography of Hermit Six Ones uses the uniqueness of horizon operation to produce philosophy of the article and induce profound introspections of life and society.

"Once the narrator is recognized in the context, it would be a constant. However, as the narrator is just a soul projection of the author or a narrative strategy, the contraposition or malposition between the narrator and the author would be a variable. In narrative perspective, the value of variables is never less than that of

\footnotetext{
${ }^{1}$ Ibid. pp. 223.

${ }^{2}$ LiuyiJushiZhuan(The Biography of Hermit Six Ones). pp.1131-32.

${ }^{3}$ Narratology:The Form and Functioning of Narrative.pp.125.

${ }^{4}$ LiuyiJushiZhuan(The Biography of Hermit Six Ones). pp.1131-32.

${ }^{5}$ ZhongguoXushixue(Chinese Narrative). pp.171.
}

${ }^{6}$ Ibid. pp.134. 
constants."1 In TheBiography of Hermit Six Ones, the malposition between the narrator and the author has penetrated the whole story, and the two haven't achieved contraposition until the six characters "The Biography of Hermit Six Ones" appeared at the end; when the third-person narration changes to the first-person identification, the narration comes to an end.We can know the identity between the narrator and the author only by backward inference. If we read the article from the title to the end, we see all malpositions and alienation between the author and the narrator. If we don't consider the fact that we know Hermit Six Ones is the assumed name of Ouyang Xiu in his old age, the point of this narrative mode is to facilitate readers to exercise their subjective initiatives for analysis and criticism of events narrated in the article, and make calm and sensible judgments.Setting of the question-answer scenario is a narrative mode to produce speculative fields. An assumed dramatic scenario that the subject and the object are in swordplays can subtly reflect introspection and satire of the author.

"Perspective mobility exists between two extremes: one goes from multiple perspectives to one perspective and enters the psychology of characters to display psychological worlds between consciousness and unconsciousness. The other extreme goes from one to multiple perspectives that jumps out of the narrative world to the author or the narrator who directly narrates. Therefore, three conditions of perspective movement are displayed: the first is normal movement; the second is that the normal scenario moves into the psychological scenario; and the third is that the normal scenario moves out to the scenarios when the author or the narrator speaks. "The Biography of Hermit Six Ones well fits the description here. From the beginning to the end, the narration moves from one extreme to the other, and three perspective movements are involved: First, Hermit Six Ones is the narrator and the guest is the audience when narration moves on the normal scenario; second, Hermit Six Ones moves into exploration and excavation of his inward world; third, Hermit Six Ones actively terminates the conversation and jumps back to his identity as a narrator for inward monologue, and the narrator and the author clearly unite at the end. In transformation and movement of the three scenarios, the narrative perspectives move with clear paths and accurate positions.

"But the first-person narrative seems to have been used mainly in the ancient world not for factual or mimetic representation, but for highly unreliable and one-sided apologias". 3 "...bristles with passages of analysis, and the story advances to a ruminative rhythm, grinding slowly but exceeding fine, with the narrator moving continually in the analytical passages from specific consideration of the characters to careful and delicate moral generalizations, couched in the first and second persons plural." ${ }^{4}$ As The Biography of Hermit Six Ones has clarified the nature of the article, we can regard the formal third-person expression as the first-person statement. In general, analytical paragraphs run through the whole article, and the subject-object setting is actually transformation between first-person and second-person narrations. Closely arranged questions raised by the object and gradually deepened answers by the subject developed "exquisite moral sublimation". Therefore, the apologia and moral sublimation in the context are extremely evident and consistent.

"The characters who tell the primary author-narrator stories often lead to stories within stories and narrations within narrations; and the self-apologists, who idealize their own lives for moral or aesthetic purposes." Consequently, acting as "Hermit Six Ones" in the context, Ouyang Xiu told his story to the author and the narrator, and the jacket structure of the story came into being. From subject-object conversations to active termination by the subject for interior monologues, the author and the narrator acting as story characters freely and clearly acknowledge the biography nature of the article; a complete narrative loop is finished. In moral and aesthetic dimensions, the author has idealized his life.

"To the extent that the narrator is characterized he will dominate the narrative, taking precedence over event and situation." "He is also defined by his resolution of those perspectives into a single, authoritative vision.... The multiple perceptions of this kind of narrator coalesce into a single reality, a single truth."7 "The

\footnotetext{
${ }^{1}$ Ibid. pp. 142 .

${ }^{2}$ Ibid. pp. 164

${ }^{3}$ Robert Scholes,James Phelan and Robert Kellogg:The Nature of Narrative[M].Oxford:Oxford University Press,2006. pp.244.
}

${ }^{4}$ Ibid. pp.197.

${ }^{5}$ Ibid. pp.245-46.

${ }^{6}$ Ibid.pp. 256 .

${ }^{7}$ Ibid. pp. 273 . 
artist, the narrator, and the protagonist are almost united and certainly share the same viewpoint on the action

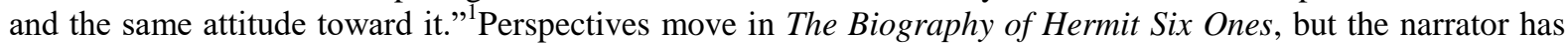
always controlled the direction of narrative perspectives, and a single authoritative vision is developed. Multiple knowledge gained by the narrator from subject-object interactions coalesce into a single reality - deep psychological reason exploration of the narrator that he should get away from officialdom chores and actively retire for scholarly activities, "a single truth" - is actually the confirmation of the truth that it is the sole path for life happiness.At last, Ouyang Xiu, the narrator and Hermit Six Ones unite into one person in the Biography. First, the interior monologues of the narrator at the last paragraph achieve unification between the narrator and Hermit Six Ones, and Ouyang Xiu as the author and the two identities in the last sentence "the biography of Hermit Six Ones" achieve a complete trinity.

The reason why so much discussion is made to analyze perspective meanings in The Biography of Hermit Six Ones is not only because they are core parts for narrative strategies and techniques, but also because "narrative works contain cultural codes, personal soul codes of the author so that vitality of works can be effectively revealed. Works are not disassembled as lifeless and mechanical parts, internal relations between narrative perspectives and the authors should be explored, and soul codes of authors contained in the works should be deeply interpreted....... Reverse thinking can be made by relying on contexts and narrative perspectives to investigate spotlights, complexes and scars in the soul bottom of the author, which is the critical path to approach the life core of the article." 2 In the final analysis, "techniques" are actually representations and means, but "Dao" contained reflects the author's true ideas and real soul. Only by taking this as the true purpose can painstaking explorations of techniques have their real values and meanings.

As a literary and cultural authority in the Song dynasty, and a great ancient master, is the lofty character described by Ouyang Xiu in his biography consistent with facts? In addition to his undeniable pioneering achievements in many cultural fields, what are some of his lofty and upright morals and merits that are highly praised by the contemporary and later generations?The famous article Funeral Oration for Ouyang Wenzhong was written by Wang Anshi gives the answer:

"Why should I feel sad for such a great life that makes you famous and highly recognized both before andafter death? For your lofty character, profound knowledge and brilliant learning, you always enjoyed a marvelous fame in articles and discussions as a renowned and celebrated master. The knowledge you stored internally is as vast as large rivers and lakes, and the glory you radiated externally is as brilliant as the sun and the moon.Your crystal and serene expressions are like howling wind and dashing rain, your elegant and convincing arguments are like swift carts and racing horses. You can know all scholars from their articles, no matter if you know or don't know them.

Alas! In the officialdom for forty years with various positions and people, you deeply feel hardship of life; facing frustrations and difficulties, experiencing depressions and sufferings, you have got your merits fairly recognized and never hidden.Under great pressure you never gave up but got renowned in the world; your courage and resolution, your determination and justice have never faded in your old age.

At the end his reign, considering the imperial succession, Emperor Renzong of the Song Dynasty said that ministers like you could be trusted for the national stability and peace. You were calm and composed to offer decisions and strategies for thousands of stability and prosperity. After great achievements were made, you didn't hesitate to retire, but your every action showed your lofty personality. Anima will never die with dust, but grow forever next to towering mountains and rushing rivers.

All common people cry and sob for you; all court officials and former friends remember and eulogize your merits." 3

In early years, Ouyang Xiu and Wang Anshi were closely associated as Ouyang Xiu had helped with the promotion of Wang Anshi. They had profound relations like a teacher and a student or friends. However, Ouyang Xiu criticized Wang Anshi for his farming reform, and refused to follow the new tax policy advocated by Wang Anshi in his jurisdiction. After deterioration of their relations, Ouyang Xiu met political persecutions from Wang Anshi. Bi Yuan of the Qing dynasty made the following record in his Xu Zizhitongjian, "On the day of Jiazi, Ouyang Xiu in Caizhou was promoted to the teacher of the crown prince and Guanwen Hall Scholar.Ouyang Xiu persisted in his merits, and was continuously slandered. When he was sixty, he applied for retirement.When he governed Qingzhou, Ouyang Xiu reported to the emperor for abolishing the Green Seedling Tax, so Wang Anshi resented him and Ouyang Xiu was more eager to retire. Feng Jing begged for his stay, but Wang Anshi replied, 'Ouyang Xiu associates with vulgar people and recommended Han Qi as a capable minister.

${ }^{1}$ Ibid. pp.269.

${ }^{2}$ ZhongguoXushixue(Chinese Narrative). pp.143.

${ }^{3}$ Wang Anshi:LinchuanXianshengWenji(The collection of Mr.Linchuan)[M].Beijing:Zhonghua Book Company,1959. pp.420 
Such a person would ruin a prefecture if he is a local governor and ruin the court if he is in the capital. What reason on earth to urge him to stay?' Therefore, many virtuous ministers left the court." 'We can see their deteriorated relations because of conflicting political views. Therefore, we also know that the funeral oration wrote by Wang Anshi may have some insincere expressions. However, the evaluations of Wang Anshi to Ouyang Xiu were appropriate. In The Biography of Hermit Six Ones, Ouyang Xiu's merits have been sufficiently reflected like what Wang Anshi has written, "your courage and resolution, your determination and justice have never faded in your old age", "2"After great achievements were made, you didn't hesitate to retire, but your every action showed your lofty personality.Anima will never die with dust, but grow forever next to towering mountains and rushing rivers." ${ }^{3}$ With the cross-reference between the evaluation from the enemy-friend poet and the biography of Ouyang Xiu, we can find agreements and objective description in the context. Whether as a senior official or an old man in the countryside, Ouyang Xiu always persisted in his merits and personality to pursue life values and resist vulgar lifestyle, and consciously assumed his social responsibilities. Such brilliant virtues have been respected for one thousand years and have been correctly expressed in the biography. It can be said that The Biography of Hermit Six Ones is a model prose for biographic narration and virtue expression.

\section{EPILOGUE}

Roland Barthes wrote in his The Rustle of Language, "It is not that the Author cannot 'return' in the Text, in his text, but he does so, one might say, as a guest; if he is a novelist, he inscribes himself there as one of his character, drawn as a figure in the carpet;his inscription is no longer privileged, paternal,alethic,but ludic:he becomes, one can say, a paper author;" "The word bio-graphyregains a strong,etymological meaning;and thereby the sincerity of the speech-act,a veritable 'cross' of literary ethics, becomes a false problem:the $I$ that writes the text is never anything but a paper $I . " 5$

Examined in perspectives of Chinese and Western narratologies, The Biography of Hermit Six Ones is undoubtedly a representative article combining contemporary virtues and personal ideals. As a cultural flag and leader, Ouyang Xiu was virtualized into the hidden base of the article, and an old scholar was well portrayed as someone who lived leisurely without bothering himself with worldly trifles, but pursuing elegant tastes, lofty merits, and contented old time. He described himself as a special figure in Chinese literary world, and a "paper author" and "paper ego" as Roland Barthes had defined.By summing up, examined in multiple perspectives of Chinese and Western narratologies, as an outstanding narrative article, The Biography of Hermit Six Ones of Ouyang Xiu unquestionably has multi-dimension values and meanings. Its sophisticated narrative techniques and profound cultural connotations have created prominent writing styles and remarkable achievements in many aspects for narrative works, and they are a great classic model contributing enormously to narrative explorations.

${ }^{1}$ Bi Yuan:XuZiZhi TongJian(Continued Comprehensive mirror to aid in government)[M].Changsha:Yuelu Press,2008.pp.100.

${ }^{2}$ LinchuanXianshengWenji(The collection of Mr.Linchuan). pp.420.

${ }^{3}$ Ibid. pp. 420 .

${ }^{4}$ Roland Barthes:The Rustle of Language[M].Translated by Richard Howard.Berkeley and Los Angeles:University of california Press,1989. pp.61.

${ }^{5}$ Ibid. pp.62. 